\title{
STUDY ON THE COUPLING AND COORDINATION DEGREE OF HIGH-QUALITY ECONOMIC DEVELOPMENT AND ECOLOGICAL ENVIRONMET IN BEIJING-TIANJIN-HEBEI REGION
}

\author{
LIAO, M. L. ${ }^{1}-$ CHEN, Y. $^{1}-$ WANG, Y. J. ${ }^{2 *}-$ LIN, M. S..$^{3 *}$ \\ ${ }^{1}$ Institute for Urban and Environmental Studies, Chinese Academy of Social Sciences \\ No. 28 Shuguangxili, Chaoyang District, Beijing, China \\ ${ }^{2}$ School of Economics and Management, University of Chinese Academy of Sciences \\ No.19(A) Yuquan Road, Shijingshan District, Beijing, China \\ ${ }^{3}$ College of Tourism, Fujian Normal University \\ No. 1 Science and Technology Road, Minhou University Town, Fuzhou, China \\ (phone: +86-10-8268-0673; fax: +86-10-8268-0673) \\ ${ }^{*}$ Corresponding authors \\ e-mail:wangyj@ucas.ac.cn; fax +86-10-8268-0673 \\ e-mail:linms@fjnu.edu.cn; fax+86-0591-2286-8726 \\ (Received $2^{\text {nd }}$ Apr 2019; accepted $11^{\text {th }}$ Jul 2019)
}

\begin{abstract}
With the rapid development of urbanization and industrialization in China, the issue of high-quality economic development and ecological environment has arisen. Taking the Beijing-TianjinHebei region as the research subject, this paper measured the comprehensive scores of economic development and ecological environment, and analyzed the coupling degree of these two systems from 2000 to 2018. According to the four degrees of coupling and coordination, this paper defined the degree of coupling and coordination between the economic development and ecological environment in BeijingTianjin-Hebei region, and put forward some policy suggestions. The result shows that, between 2000 and 2018, (1) the coupling degree of economic development and ecological environment in Beijing-TianjinHebei region is $C \in[0.2,1]$, which is changing with time, and has gone through all stages of coupling; the coordination degree of economic development and ecological environment in Beijing-Tianjin-Hebei region is $\mathrm{D} \in[0.1,0.5]$, which is in the low-middle stage. (2) The coupling degree of economic development and ecological environment in Beijing-Tianjin-Hebei region shows a trend of increasing first and then decreasing, while the coordination degree shows a rising trend, and remains more or less flat compared to the coupling degree.
\end{abstract}

Keywords: high-quality development, ecological development, coupling degree, coordination degree, Beijing-Tianjin-Hebei Region

\section{Introduction}

China's economic construction has achieved remarkable results since the reform and opening up, with an average growth rate of $9.78 \%$ from 1978 to 2011. Affected by the global economic crisis in 2012, China's economic growth has slowed down, with an average growth rate of $7.2 \%$ from 2012 to 2017. It has become a new norm for China's economic growth to shift from high-speed to medium-high speed. A basic feature of the new era for China's economic development is the transition from a phase of rapid growth to a stage of high-quality development, and the promotion of high-quality economic development is an essential requirement for the new normal in economic development (Cheng and Qiu, 2018). 
In 1978, China's urbanization level was only $17.9 \%$, while by the end of 2018 , it was up to $59.58 \%$. According to The Report on Chinese Industrialization issued by the Chinese Academy of Social Sciences, China has entered the second stage of the lateindustrialization since 2015, with an overall industrialization level index of 84 . What's more, with the industrialization level index of 95, 76 and 71, respectively, all the eastern, central and western regions in China have entered the stage of the lateindustrialization $(\mathrm{Hu}, 2017)$. The economic growth in the middle and late stages of industrialization mainly depends on the growth of the secondary industry, that is, China's economic development relies heavily on industries with high energy consumption and high pollution. The rapid development of China's economy and the promotion of urbanization and industrialization have caused serious damage to the ecological environment, and the destruction of the ecological environment has also inhibited the economic growth (Liao and Wang, 2019). Since 2016, many cities in China have been affected by haze, especially cities in the Beijing-Tianjin-Hebei Region. Within the Bohai Economic Circle, the Beijing-Tianjin-Hebei Region is not only the largest and most sophisticated economic zone in Northern China, but also an important political and cultural center of China. However, since the economic development in the Beijing-Tianjin-Hebei Region is dependent on high-energy-consumption and highpollution industries, there have been serious environmental problems in the BeijingTianjin-Hebei Region. And the economic development in this region has transformed to the coordination between high-quality economic development and the development of ecological environment. Therefore, this paper analyzed the characteristics of each stage of the economic and environmental development based on the measurement of the coupling degree between the economic development and the ecological environment system in the Beijing-Tianjin-Hebei region, and provided a basis for the high-quality economic development there.

\section{Literature Review}

At the 19th National Congress of the Communist Party of China, president Xi Jinping declared that "China's economy has been transitioning from a phase of rapid growth to a stage of high-quality development. This is a pivotal stage for transforming our growth model, improving our economic structure, and fostering new drivers of growth." The transformation of China's economy from a phase of rapid growth to a stage of high-quality development is the essential requirement for the new normal in economic development (Sheng, 2018). In the fundamental economic theories, highquality development can be expressed as the mode, structure and momentum of economic development living up to its real nature, which is to satisfy people's growing needs for a better life (Jin, 2018). Shi et al. (2018) measured the high-quality economic development index based on the two dimensions of economic growth fundamentals and social achievements. The results show that time span of China's inter-provincial economic growth quality fluctuation cycle has been widening gradually, the distribution of economic growth in the Eastern, central and Western China is unbalanced and difficult to close in short term, and the quality of economy growth of China will enter a long-term uptrend channel. The high-quality economic development refers to the economic development stressing both quantity and quality of economic growth, and lay emphasis on the quality of economic growth. The existing researches on economic development have been mainly conducted from the 
perspectives of sources of economic growth, reasons for slow-speed development of economy and the evaluation of low-carbon or green economy. According to the study of Shen et al. (2011), though the development model oriented by manufacturing and service industries, with urbanization as space carrier and marketization as system, can promote the sustainable and high-speed economic growth in China, the restraints on this model is increasing. Nie et al. (2011) found there has been misallocation of resources in state-owned enterprises, and almost no reallocation of resources within the industries, which contributed to the inefficiency of China's manufacturing industry. Zhuang et al. (2014) evaluated the low-carbon development of several cities in China and made comparisons with that of international cities. Chen et al. (2018) analyzed the relationship between the governance of haze pollution and high-quality economic development, and believed that the improvement of economic development quality is the premise of the transformation of economic development mode, and the governance of haze pollution can help improve the quality of the atmospheric environment and economic development, and promote the high-quality development of economy in return.

"Coupling" is a concept derived from the mechanical nexus between two parts of something. From the perspective of ecology, "coupling" refers to the interaction, transition and development of two or more system elements or subsystems (Zhang et al., 2016). The elements in a coupling system are closely related, and their cooperation can improve the productivity and ecological function of the system. The coupling construction of the ecosystem is actually the development process of the ecosystem from disorder to order (Liu, 2016). Since urbanization involves a series of coupling processes, coupling simulation and optimization are widely applied in solving planning problems and rapid development of regional economy ( $\mathrm{Li}$ et al., 2011). Using the panel data of Lianyungang, Li et al. (2012) analyzed the challenges of rapid urbanization in coastal cities with a coupling and coordination degree model focusing on the degree of coordination between urbanization and the environment, and found that the dynamic of coordination between urbanization and environment showed a Ushaped curve. Lei et al. (2015) investigated the relationship between urbanization and air environment from the perspective of coupling coordination theory, and found that the degree of coordinated coupling between urbanization and air environment exhibited an S-shaped curve, indicating that the slightly unbalanced development of Wuhan has turned into the barely balanced development, and has entered a period of superiorly balanced development, with the air environment lagging. Wang et al. (2014) conducted a quantitative analysis of the coupling relation between urbanization and ecological environment in Nanchang and Jiujiang urban belts, and the results showed that the coordination degree of Nanchang rises at a faster speed, reaching a moderate balance level, while that of Jiujiang remains at a low level. Therefore, Nanchang and Jiujiang urban belts should further transform its economic growth model, optimize the industrial structure, improve its technology and embark on a newurbanization path featuring resource-saving, low carbon emission, environmentalfriendly and cost effective. You (2016) assessed the coordinated degree of urbanization by quantifying four involved processes (demographic, social, economic and spatial) in Shanghai from 1952 to 2012, and found that the demographic urbanization advanced continuously and roughly presented a U-shaped trend. Guo et al. (2015) examined the coupling relationship between urbanization and environment in the Huaihe River Basin from both exploratory and analytical perspectives. The 
results showed the degree of coupling and the degree of policy coordination appeared to fluctuate over time.

The existing researches on the coupling relationship between high-quality economic development and eco-environmental protection are mainly conducted in the Yangtze River delta, farming-pastoral zones in northern China and mountainous areas, with the coupling coordination degree model and qualitative analysis. Zhang et al. (2015) analyzed the coupling and coordination relationship between economic development and ecological environment system from 1999 to 2003 in the extensive Yangtze River delta with the coupling coordination degree model, and found that the coupling of economic development and ecological environment was in the running-in stage, while the coordination degree of economic development and ecological environment was moderate. Based on the analysis of coupling relationship between regional economy and ecological environment, Jiang et al. (2010) established a dynamic coupling model of coordinated development of the regional economy and ecological environment, and studied the coordinated development of economy and ecological environment in Jiangsu Province. The results showed that, between 1995 and 2007, the economic development index of Jiangsu Province showed a rapid growth trend, while the index of ecological environment system showed a slow growth trend with several fluctuations, the economy and ecological environment of Jiangsu Province were developing harmoniously. Zhang et al. (2010) predicted the coordinated development of economy and ecological environment of farming-pastoral zone in northern China in the future ten years with a variety of methods. Hu et al. (2012) studied the coupling modes and implementation forms of the coordinated development of economy and ecological environment in the lake basins of Yunnan Plateau. Wang et al. (2013) estimated the coupling and coordination degree of tourism economic development and ecological environment of the forest parks in Shanxi Province. Fang et al. (2016) analyzed the theoretical framework and methodology of the interactive coupled effects between urbanization and eco-environment in megaurban agglomerations with the method of qualitative analysis. In addition, some scholars have studied the response of ecological environment to marine economy development and its influencing factors in Bohai Bay Rim Area (Li et al., 2017; Li and Gao, 2017), explored the coupling relationship between economic development and ecological environment in poverty-stricken areas (Cao et al., 2016; Liu et al., 2007), and analyzed the coupling relationship between the benefit of economic development and ecological environment quality along the Silk Road Economic Belt (Wang, 2018).

It can be seen that, although there are many researches on the relationship between economic development and ecological environment, few of them were conducted in the Beijing-Tianjin-Hebei region, and even fewer from the perspective of high-quality economic development. What's more, the existing researches mainly focus on the economic growth, while this paper tends to take a comprehensive consideration of the scale, level and potential of the economic development, that is, study the coupling relationship between economic development and environmental protection from the perspective of high-quality economic development. The economic growth in China has entered a period of transformation with quality as its first priority, and the economic growth in Beijing-Tianjin-Hebei Region is crucial to China's economic growth. After a long term high-speed economic development in the Beijing-TianjinHebei Region, problems such as the singularization of industrial structure, exhaustion 
of resources and deterioration of ecological environment have been emerging, and the "crowding-out effect" of backward production capacity in the core area is getting more and more serious, leading to an outward flow of core industries. Therefore, this paper conducted the research on the coupling relationship between economic growth and ecological environment in the Beijing-Tianjin-Hebei Region from the perspective of high-quality economic development, supplemented the coupling theory of economy and ecological environment with the concept of high-quality development, and provided guidance for coordinating the economic development and eco-environmental protection in the Beijing-Tianjin-Hebei Region.

\section{Materials and Methods}

\section{Research Method}

\section{Improved entropy method}

The entropy method is a method for determining the weight of index according to the amount of information transmitted by each index to the decision maker, which excludes the influence of subjective factors on weighting and the overlap of information brought by multiple index. In order to avoid the shortcomings of the traditional entropy method, it is necessary to process the original data of the index, that is the improved entropy method. It can be calculated as follows:

\section{Standardize}

As there is a dimension between the economic system and the ecological environment system, the index should be standardized.

$$
u_{i j}=\frac{x_{i j}-\min \left(x_{i j}\right)}{\max \left(x_{i j}\right)-\min \left(x_{i j}\right)}
$$

uij is the positive index;

$$
u_{i j}=\frac{\max \left(x_{i j}\right)-x_{i j}}{\max \left(x_{i j}\right)-\min \left(x_{i j}\right)}
$$

uij is the negative index;

uij refers to the $j$-th index in the $i$-th system, and the value of uij is $x i j(i=1,2 ; j=1,2$, ...n), with $\max (x i j)$ refers to the maximum value and $\min (x i j)$ the minimum value of xij.

\section{Calculate}

Calculate the proportion of index uij:

$$
\mathrm{R}_{i j}=\frac{u_{i j}}{\sum_{i=1}^{m} u_{i j}}
$$


Measure the entropy of each index:

$$
e_{j}=\frac{-1}{\ln m^{*} \sum_{i=1}^{m} R_{i j} \ln R_{i j}}
$$

Calculate the difference coefficient of each index:

$$
g_{j}=1-e_{j}
$$

The larger the value of $\mathrm{gj}$ is, the more important the index is in the evaluation system.

Calculate the weight of each index:

$$
w_{i j}=\left(1-e_{j}\right) /\left(n-\sum_{j=1}^{n} e_{j}\right) \quad \mathrm{j}=1,2, \ldots \mathrm{n}
$$

Calculate the synthetical value of the system:

$$
V_{j}=\sum_{j=1}^{n} w_{j} R_{i j} \quad \mathrm{j}=1,2, \ldots \mathrm{n}
$$

\section{The Coupling and Coordination Degree Model}

The coupling degree is used to describe the degree of influence among the system or elements (Liu et al., 2011), while the coordination degree is the degree of harmony between systems or elements of the system in the process of development, which reflects the tendency of a system from disorder to order (Wu et al., 1997). It can be seen that, the coupling degree and coordination degree are two different indicators, with the coupling degree reflects the strength of interaction between two parties, regardless of advantages or disadvantages; and the coordination degree is the degree of good coupling in the interaction, reflecting the quality of coordination. Therefore, the research has been conducted from the following two aspects:

\section{Coupling degree function}

Construct a coupling degree function of high-quality economic development and eco-environmental protection, that is:

$$
C=\sqrt{U_{1} U_{2}} /\left(U_{1}+U_{2}\right)
$$

Among them, the value of $\mathrm{C}$ is between 0 and $1 . \mathrm{C}=0$ indicates that there is no coupling relationship between high-quality economic development and eco-environmental protection, and $\mathrm{C}=1$ indicates that there is a good coupling between high-quality economic development and eco-environmental protection.

\section{Coupling and coordination degree function}

The coupling and coordination degree function of high-quality economic development and eco-environment protection is: 


$$
\begin{gathered}
\mathrm{D}=\sqrt{\mathrm{C} \cdot \mathrm{T}} \\
\mathrm{T}=\alpha U_{1}+\beta U_{2}
\end{gathered}
$$

where $\mathrm{D}$ is the coupling and coordination degree, and $\mathrm{T}$ is the comprehensive coordination index of high-quality economic development and eco-environmental protection, representing the coordination index of high-quality economic development and eco-environmental protection at each coupling level. $\alpha$ and $\beta$ represent the contribution rate of each system, that is, the contribution coefficient of high-quality economic development and eco-environmental protection. Since there is an interaction between high-quality economic development and eco-environmental protection, both $\alpha$ and $\beta$ are 0.5 . Similar to the coupling degree, the coordination degree can also be divided into 4 levels (see Table 1).

\begin{tabular}{|c|c|c|c|c|}
\hline $\begin{array}{c}\text { Value of coupling } \\
\text { degree }\end{array}$ & $\begin{array}{l}\text { Phase of } \\
\text { coupling }\end{array}$ & $\begin{array}{l}\text { Value of coupling and } \\
\text { coordination degree }\end{array}$ & $\begin{array}{l}\text { Type of coupling and } \\
\text { coordination }\end{array}$ & Phase of coordination \\
\hline $0<\mathrm{C} \leq 0.3$ & $\begin{array}{l}\text { Separation } \\
\text { phase }\end{array}$ & $0<\mathrm{D} \leq 0.3$ & $\begin{array}{l}\text { Low coupling and } \\
\text { coordination degree }\end{array}$ & $\begin{array}{c}\text { Separation phase with low } \\
\text { coordination }\end{array}$ \\
\hline $0.3<\mathrm{C} \leq 0.5$ & $\begin{array}{l}\text { Antagonistic } \\
\text { phase }\end{array}$ & $0.3<\mathrm{D} \leq 0.5$ & $\begin{array}{l}\text { Medium coupling and } \\
\text { coordination degree }\end{array}$ & $\begin{array}{l}\text { Antagonistic phase with } \\
\text { medium coordination }\end{array}$ \\
\hline $0.5<\mathrm{C} \leq 0.8$ & $\begin{array}{l}\text { Running-in } \\
\text { phase }\end{array}$ & $0.5<\mathrm{D} \leq 0.8$ & $\begin{array}{l}\text { High coupling and } \\
\text { coordination degree }\end{array}$ & $\begin{array}{l}\text { Running-in phase with high } \\
\text { coordination }\end{array}$ \\
\hline $0.8<\mathrm{C} \leq 1$ & $\begin{array}{l}\text { Coupling } \\
\text { phase }\end{array}$ & $0.8<\mathrm{D} \leq 1$ & $\begin{array}{l}\text { Extremely high } \\
\text { coupling and } \\
\text { coordination degree }\end{array}$ & $\begin{array}{c}\text { Coupling phase with extremely } \\
\text { high coordination }\end{array}$ \\
\hline
\end{tabular}

Table 1. The level of coupling and coordination degree

\section{Index Selection}

Due to the wide variety of influencing factors involved in urban economic development and ecological environment, as well as the complex interaction mechanism among them, their development status and impacts cannot be reflected with only one indicator. Therefore, we would like to select indicators and construct an indicator system based on existing researches (see Table 2).

\section{Results}

With the improved entropy method, we standardized the raw data of the BeijingTianjin-Hebei region from 2000 to 2018 , and calculated the entropy and weight of each indictor in the economic development and ecological environment system of Beijing, Tianjin and Hebei. The synthesis scores of economic development and ecological environment systems in the Beijing-Tianjin-Hebei Region are shown in Table 3.

It can be seen from Table 3 that:

(1) From the perspective of economic development, there is an uptrend in synthesis scores of the economic development in the Beijing-Tianjin-Hebei region from 2000 to 2018, with Beijing developed the fastest in 2003-2011, followed by Tianjin and Hebei. By the year of 2011, Tianjin ranked the first in economic development, followed by Hebei and Beijing. It can be explained by Beijing's high-speed economic development in the preceding years brought by regulatory policies and convenient transportation. 


$$
-11076 \text { - }
$$

Table 2. The index system and weight of index of the coupling and coordination degree model of economic development and ecological environment

\begin{tabular}{|c|c|c|c|}
\hline System & Target & Index & Weight \\
\hline \multirow{3}{*}{$\begin{array}{c}\text { Economic } \\
\text { development } \\
\text { system }\end{array}$} & $\begin{array}{c}\text { Scale of } \\
\text { economic } \\
\text { development }\end{array}$ & $\begin{array}{c}\text { GDP (100 million yuan) } \\
\text { Fiscal revenue (100 million yuan) } \\
\text { Total fixed assets investment (100 million yuan) } \\
\text { Gross industrial production (100 million yuan) }\end{array}$ & $\begin{array}{l}0.066 \\
0.084 \\
0.086 \\
0.065\end{array}$ \\
\hline & $\begin{array}{l}\text { Level of } \\
\text { economic } \\
\text { development }\end{array}$ & $\begin{array}{c}\text { Per capita GDP (10 thousand yuan) } \\
\text { Rural per capita net income (yuan) } \\
\text { Urban per capita disposable income (yuan) }\end{array}$ & $\begin{array}{l}0.061 \\
0.067 \\
0.069\end{array}$ \\
\hline & $\begin{array}{l}\text { Potential of } \\
\text { economic } \\
\text { development }\end{array}$ & $\begin{array}{c}\text { Local fiscal revenue in GDP (\%) } \\
\text { Per capita expenditure on science, education, culture, health and other } \\
\text { undertakings (yuan) } \\
\text { The number of people receiving undergraduate or junior college education } \\
\text { (10 thousand people) } \\
\text { The number of the employed in urban area (10 thousand people) }\end{array}$ & $\begin{array}{l}0.072 \\
0.043 \\
0.024 \\
0.105\end{array}$ \\
\hline \multirow{2}{*}{$\begin{array}{l}\text { Ecological } \\
\text { environment } \\
\text { system }\end{array}$} & $\begin{array}{l}\text { Ecological } \\
\text { environment } \\
\text { pollution }\end{array}$ & $\begin{array}{l}\mathrm{SO}_{2} \text { emission (10 thousand tons) } \\
\text { Pollutant discharge_chemical oxygen demand (COD) (10 thousand tons) } \\
\text { Production of industrial solid waste (10 thousand tons) }\end{array}$ & $\begin{array}{l}0.015 \\
0.042 \\
0.052\end{array}$ \\
\hline & $\begin{array}{l}\text { Ecological } \\
\text { environment } \\
\text { management }\end{array}$ & $\begin{array}{l}\text { Green coverage rate in urban built-up areas (\%) } \\
\text { Disposal of industrial solid waste (10 thousand tons) } \\
\text { Sewage treatment capacity in urban areas (10 thousand cubic meters per } \\
\text { day) }\end{array}$ & $\begin{array}{l}0.030 \\
0.077 \\
0.043\end{array}$ \\
\hline
\end{tabular}

Table 3. Synthesis scores of economic development and ecological environment systems in the Beijing-Tianjin-Hebei Region from 2000 to 2018

\begin{tabular}{|c|c|c|c|c|c|c|}
\hline Year & $\begin{array}{c}\text { Beijing } \\
\text { Economic } \\
\text { development }\end{array}$ & $\begin{array}{c}\text { Beijing } \\
\text { Ecological } \\
\text { environment }\end{array}$ & $\begin{array}{c}\text { Tianjin } \\
\text { Economic } \\
\text { development }\end{array}$ & $\begin{array}{c}\text { Tianjin } \\
\text { Ecological } \\
\text { environment }\end{array}$ & $\begin{array}{c}\text { Hebei } \\
\text { Economic } \\
\text { development }\end{array}$ & $\begin{array}{c}\text { Hebei } \\
\text { Ecological } \\
\text { environment }\end{array}$ \\
\hline 2000 & 0.02 & 0.03 & 0.01 & 0.14 & 0.07 & 0.09 \\
\hline 2001 & 0.03 & 0.06 & 0.02 & 0.14 & 0.07 & 0.09 \\
\hline 2002 & 0.06 & 0.08 & 0.03 & 0.12 & 0.07 & 0.09 \\
\hline 2003 & 0.08 & 0.11 & 0.05 & 0.16 & 0.04 & 0.10 \\
\hline 2004 & 0.12 & 0.09 & 0.07 & 0.14 & 0.06 & 0.10 \\
\hline 2005 & 0.16 & 0.13 & 0.10 & 0.12 & 0.10 & 0.11 \\
\hline 2006 & 0.19 & 0.16 & 0.13 & 0.12 & 0.13 & 0.11 \\
\hline 2007 & 0.24 & 0.18 & 0.18 & 0.11 & 0.17 & 0.12 \\
\hline 2008 & 0.28 & 0.21 & 0.22 & 0.12 & 0.22 & 0.14 \\
\hline 2009 & 0.32 & 0.21 & 0.26 & 0.11 & 0.25 & 0.15 \\
\hline 2010 & 0.37 & 0.21 & 0.33 & 0.11 & 0.32 & 0.18 \\
\hline 2011 & 0.44 & 0.13 & 0.44 & 0.07 & 0.41 & 0.10 \\
\hline 2012 & 0.49 & 0.12 & 0.52 & 0.07 & 0.51 & 0.10 \\
\hline 2013 & 0.54 & 0.13 & 0.57 & 0.09 & 0.57 & 0.16 \\
\hline 2014 & 0.57 & 0.14 & 0.62 & 0.09 & 0.61 & 0.17 \\
\hline 2015 & 0.63 & 0.17 & 0.66 & 0.13 & 0.66 & 0.16 \\
\hline 2016 & 0.67 & 0.24 & 0.68 & 0.19 & 0.71 & 0.22 \\
\hline 2017 & 0.65 & 0.20 & 0.70 & 0.17 & 0.70 & 0.19 \\
\hline 2018 & 0.66 & 0.15 & 0.73 & 0.19 & 0.75 & 0.16 \\
\hline
\end{tabular}

Data sources: Calculated according to the China City Statistical Yearbook

(2) From the perspective of ecological environment, the low scores of ecological environment system in the Beijing-Tianjin-Hebei Region may be due to the economic development mode and the rapid pace of development, which has caused serious damages to the ecological environment, and the ecological environment destruction, in 
turn, has restricted the economic development over time. The significant fluctuation in synthesis scores of ecological environment systems after 2010 can be explained by the impact of high-speed of economic development and urbanization on ecological environment, which has led to the energy resources depletion, environmental pollution and ecological imbalance. However, the improvement of synthesis scores of ecological environment systems after 2013 may be related to the economic regulatory policies which laid more emphasis on quality rather than speed of economic development.

(3) Through the comparison of the economic development and ecological environment in the Beijing-Tianjin-Hebei region, we can see that the score of economic development was lower than that of ecological environment from 2000 to 2018. What's more, during the study period, the score of economic development continued to rise, while that of the ecological environment continued to decline, indicating that there is a negative correlation between economic development and ecological environment in Beijing-Tianjin-Hebei region.

\section{Discussion}

\section{Characteristics of time variation}

The coupling degree (C) and the coordination degree (D) of the Beijing-TianjinHebei region from 2000 to 2018 have been calculated according to the formula (see Figure 1).

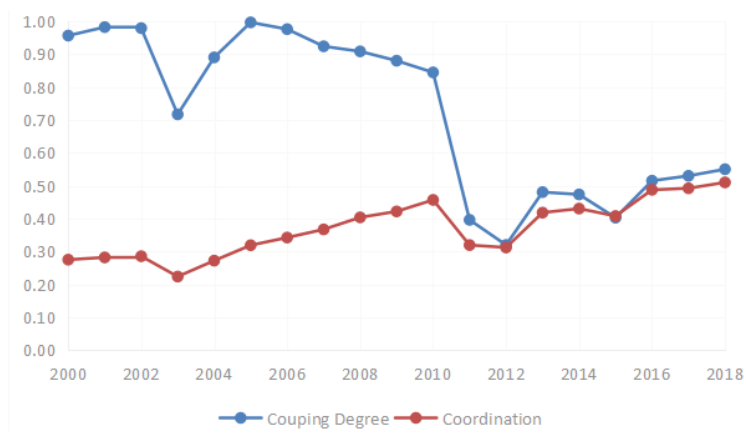

Figure 1. Mean value of the coupling and coordination degree between economic development and ecological environment system in the Beijing-Tianjin-Hebei Region in 2000-2018

It can be seen from Figure 1 that, the coupling and coordination degree between economic development and ecological environment system in Beijing-Tianjin-Hebei Region in 2000-2018 fluctuated greatly. The years from 2000 to 2002 can be seen as the coupling phase and the year of 2003 as the running-in phase, which can ben explained as the lagged effect of China's accession to the WTO in 2001 on the economic development in Beijing-Tianjin-Hebei Region. With the years from 2004 to 2010 as another coupling phase, the years from 2000 to 2010 can be taken as the coupling phase on the whole. During this period, China's economy has been developing rapidly and the environmental problems have not yet emerged, but the coupling degree between economic development and ecological environment in the Beijing-Tianjin-Hebei region has shown a downward trend. In 2011, the coupling degree dropped to 0.4 suddenly and has not exceed 0.5 until 2018. The years of 2011-2018 is the antagonistic phase of the coupling relationship between economic development and ecological environment in 
Beijing-Tianjin-Hebei region. It is in line with the reality that China's economic development has entered a new normal of medium-to-high-speed growth and is accompanied by the frequent occurrence of environmental pollution problems such as haze. In order to resolve the contradiction between economic development and environmental protection, the coordinated development in the Beijing-Tianjin-Hebei region should be strengthened and the integration of industrial layout should be promoted. What's more, the development of the Circum-Bohai Sea Economic Zone can be promoted by exploring the effective path of ecological civilization construction, strengthening the complementary advantages of Beijing, Tianjin and Hebei, and enhancing the coordination of population, economy, resources and environment in the Beijing-Tianjin-Hebei region.

The analysis of coordination degree shows that, from 2000 to 2018, the coordination degree of Beijing-Tianjin-Hebei Region has been increasing steadily with sight fluctuations, which is at a low-to-moderate level. This can be explained by the high level of urbanization and the continuous optimization of industrial structure, which are not in line with the environmental protection.

From 2000 to 2011, there was a great difference between the coupling degree and coordination degree of economic development and eco-environmental protection. It can be explained by the damage to the ecological environment brought by the rapid development of economy. Since 2011, the gap between coupling degree and coordination degree has been narrowed because of the adjustment of industrial structure and the transformation or upgrading of economy, which has taken the ecological civilization construction and economic development into full consideration.

\section{Characteristics of spatial pattern}

The coupling and coordination degrees between economic development and ecological environment of Beijing, Tianjin and Hebei have been calculated by SPSS (see Table 4). It can be seen from Table 4 that, there were large fluctuations in both coupling and coordination degree of Beijing, Tianjin and Hebei after 2010. The coupling relationship between economic development and ecological environment in Beijing has experienced the coupling phase of 2000-2010, the antagonistic phase of 2011-2015, and the running-in phase of 2016-2018. This can be explained by the highspeed economic development and the good environmental condition in 2000-2010. Since 2011, the economic development has slowed down and the problems of environmental pollution has emerged. At present, with the goal of high-quality economic development, Beijing has made more efforts to protect the environment, and the coupling relationship between economic development and ecological environment has been optimizing. The coordination degree between economic development and ecological environment in Beijing has been increasing steadily with slight fluctuations, which is moderate in general. There has been a drastic fluctuation in the coupling degree of Tianjin from 2000 to 2018, with the years of 2004-2008 as the coupling phase. It can be explained by the economic transition and upgrade, or the interaction between various influencing factors of the two systems and the unbalanced economic development. The coupling relationship between economic development and ecological environment of Hebei showed the same trend as that of Beijing, but its coupling degree is lower than that of Beijing, which can be explained by the unbalanced economic and social development, the unreasonable industrial structure, and the serious impact of external factors. 
Table 4. Coupling and coordination degree of economic development and ecological environment in the Beijing-Tianjin-Hebei Region from 2000 to 2018

\begin{tabular}{c|c|c|c|c|c|c}
\hline Year & $\begin{array}{c}\text { Coupling } \\
\text { degree of } \\
\text { Beijing }\end{array}$ & $\begin{array}{c}\text { Coordination } \\
\text { degree of Beijing }\end{array}$ & $\begin{array}{c}\text { Coupling } \\
\text { degree of } \\
\text { Tianjin }\end{array}$ & $\begin{array}{c}\text { Coordination } \\
\text { degree of } \\
\text { Tianjin }\end{array}$ & $\begin{array}{c}\text { Coupling } \\
\text { degree of } \\
\text { Hebei }\end{array}$ & $\begin{array}{c}\text { Coordination } \\
\text { degree of Hebei }\end{array}$ \\
\hline 2000 & 0.97 & 0.15 & 0.12 & 0.10 & 0.96 & 0.28 \\
2001 & 0.76 & 0.18 & 0.25 & 0.14 & 0.98 & 0.28 \\
2002 & 0.93 & 0.25 & 0.38 & 0.17 & 0.98 & 0.29 \\
2003 & 0.96 & 0.31 & 0.50 & 0.23 & 0.72 & 0.22 \\
2004 & 0.97 & 0.32 & 0.80 & 0.29 & 0.89 & 0.27 \\
2005 & 0.98 & 0.37 & 0.98 & 0.33 & 1.00 & 0.32 \\
2006 & 0.98 & 0.41 & 0.99 & 0.35 & 0.98 & 0.34 \\
2007 & 0.96 & 0.45 & 0.88 & 0.35 & 0.92 & 0.37 \\
2008 & 0.96 & 0.48 & 0.82 & 0.37 & 0.91 & 0.40 \\
2009 & 0.91 & 0.49 & 0.72 & 0.37 & 0.88 & 0.42 \\
2010 & 0.86 & 0.50 & 0.56 & 0.35 & 0.84 & 0.46 \\
2011 & 0.49 & 0.37 & 0.20 & 0.23 & 0.40 & 0.32 \\
2012 & 0.41 & 0.35 & 0.17 & 0.22 & 0.32 & 0.31 \\
2013 & 0.37 & 0.35 & 0.22 & 0.27 & 0.48 & 0.42 \\
2014 & 0.39 & 0.37 & 0.19 & 0.26 & 0.47 & 0.43 \\
2015 & 0.46 & 0.43 & 0.30 & 0.34 & 0.40 & 0.41 \\
2016 & 0.60 & 0.52 & 0.47 & 0.45 & 0.52 & 0.49 \\
2017 & 0.64 & 0.55 & 0.49 & 0.50 & 0.52 & 0.55 \\
2018 & 0.67 & 0.53 & 0.53 & 0.52 & 0.55 & 0.55 \\
均值 & 0.75 & 0.39 & 0.50 & 0.31 & 0.72 & 0.38 \\
\hline
\end{tabular}

Data sources: Calculated according to the China City Statistical Yearbook

On the whole, the coordination degree of economic development and ecological environment in Beijing-Tianjin-Hebei region shows an upward trend with some slight fluctuations. However, the coordination degrees of economic development and ecological environment in Beijing, Tianjin and Hebei are all at the coupling phase with low and medium coordination, which indicates that, though the advantages in ecological environment have not been fully transformed into advantages in economic development, there has already been a virtuous circle between economic development and ecological environment.

\section{Types of urban development}

According to the coupling and coordination degree of urban economic development and ecological environment, the cities can be divided into four types: high coupling \& high coordination degree, high coupling \& low coordination degree, low coupling \& high coordination degree, low coupling \& low coordination degree. In cities with high coupling \& high coordination degree, the development of economy and ecological environment are promoted together, so that, the emphasis should be laid on the cultivation of talents, transformation of development mode, optimization of industrial structure, protection of ecological environment and improvement of treatment efficiency of municipal waste and pollutants, forming a pattern of synchronous development of economy and ecological environment. The high coupling \& low coordination degree indicates that although the economy is developing rapidly, the development of ecological environment is restricted by the local environmental carrying capacity. Therefore, the development mode should be transformed immediately so as to coordinated the development of economy and ecological environment, that is, enhancing the protection of ecological environment, giving full play to the advantages 
of local resource endowment, developing the industries with local characteristics, adjusting the industrial structure, replacing the extensive development modes with green and high-efficient ones, and laying a solid foundation for the sustainable development in the future. Cities with low coupling \& high coordination degree should be developed in a low energy-consumption, green and low-carbon development mode, which lays more emphasis on publicizing the advantages of local ecological environment, attracting foreign investment, developing industries with local characteristics and accelerating the economic development. Low coupling \& low coordination degree may be resulted from the restrictions of historical and natural conditions. With the backward economic development and the crying need for eco-environmental protection, the extensive development mode have to be adjusted, the protection and modification of ecological environment have to be strengthened, the development of economy and ecological environment have to be coordinated through reasonable planning and implementation of various preferential policies for talent introduction.

The distributions of the mean values of coupling and coordination degree between economic development and ecological environment in the Beijing-Tianjin-Hebei Region from 2000 to 2016 are shown in Figure 2. It can be seen that, Beijing, Tianjin and Hebei are all regions with high coupling \& low coordination degree, which indicates that though the degrees of urbanization and industrialization in these three regions are relatively high, and the economy is developing rapidly as well, the ecological environment has been damaged severely.

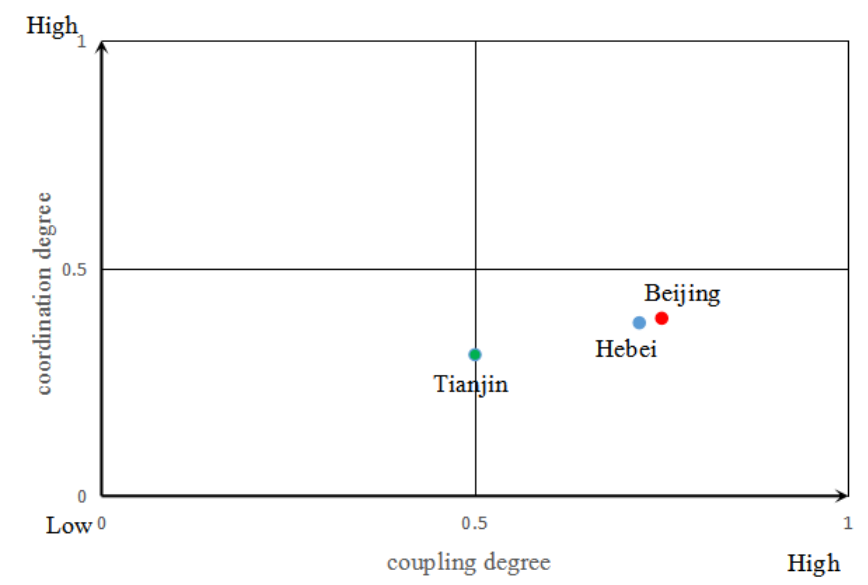

Figure 2. Distribution of coupling and coordination degree in the Beijing-Tianjin-Hebei Region

\section{Conclusions and policy recommendations}

\section{Conclusions}

Taking the Beijing-Tianjin-Hebei region as the research object, this paper measured the comprehensive scores of economic development and ecological environment, and analyzed the coupling degree of these two systems from 2000 to 2018. According to the four degrees of coupling and coordination, this paper defined the the degree of coupling and coordination between the economic development and ecological environment in Beijing-Tianjin-Hebei region, and put forward some policy suggestions. The result shows that, between 2000 and 2018, (1) the coupling degree of economic development and ecological environment in Beijing-Tianjin-Hebei region is $C \in[0.2,1]$, which is 
changing with time, and has gone through all stages of coupling; the coordination degree of economic development and ecological environment in Beijing-Tianjin-Hebei region is $D \in[0.1,0.5]$, which is in the low-middle stage. (2) The coupling degree of economic development and ecological environment in Beijing-Tianjin-Hebei region shows a trend of increasing first and then decreasing, while the coordination degree shows a rising trend, and remains about flat compared with the coupling degree.

\section{Policy recommendations}

Since the reform and opening up, with the dependence on the secondary industry, the relationship between economic development and ecological environment in the BeijingTianjin-Hebei region is characterized by high coupling and low coordination. In order to build a world-class urban agglomeration with strong international competitiveness and promote the high-quality development driven by national innovation, the relationship between economic growth and environmental protection in the Beijing-Tianjin-Hebei region should be coordinated, and the high-quality development in coordination should be promoted by constructing a sophisticated economic structure.

First of all, the industrial integration in the Beijing-Tianjin-Hebei Region should be promoted to narrow the gap between industrial base and industrial advantages. By giving priority to the development of the tertiary industry, upgrading the structure of manufacturing and service industries, cultivating high-tech industries, and exploring new patterns for industrial development, the quality and efficiency of the economic development in the Beijing-Tianjin-Hebei region will be improved.

Second, the concept of green development should be established. In the process of high-quality economic development in the Beijing-Tianjin-Hebei region, it is necessary to bear the goal of energy conservation and increasing the resource utilization rate in mind, so as to promote the development of green cities continuously and integrate the concept of green development into the economic and social development.

Third, implement the innovation-driven development strategy vigorously. The innovation-driven development strategy is the inevitable requirement for promoting the transformation of economic development mode and the switch of growth momentum in Beijing-Tianjin-Hebei region. It is necessary to build a high-tech and advanced economic structure and give full play to the leading role of Beijing. Promote the organic unity and coordination of the industry chain, value chain, innovation chain and service chain by improving the industry chain, enhancing the value chain, optimizing the innovation chain and expanding the service chain.

Finally, promote the coordinated development of population in Beijing-TianjinHebei region. As the main migration destinations in the Beijing-Tianjin-Hebei region, the pressure on resources and environment carrying capacity in Beijing and Tianjin has been increasing with the growth of population. Therefore, the intellectual and information resources of urban development should be coordinated to promote the highquality economic development in the Beijing-Tianjin-Hebei region. Taking the opportunity of the construction of the Xiong' an New Area, confine the rapid growth of population in Beijing and transfer the population to Hebei orderly. Promote the rational allocation of human resources and other high-end resources in Beijing-Tianjin-Hebei region, contribute to the coordinated development of industries and promote the industrial upgrading of other regions of the country. 


$$
-11082 \text { - }
$$

Acknowledgements. The study was funded by the Program for Risk Assessment of Climate Change and Adaptive Mode of Production, Livelihood and Eco-environment in Xiongan New Area of the Ministry of Science and Technology of China (2018YFA0606304); Program for National Conditions Survey of CASS Thinktank for Eco-civilization Studies (STWM2019C001); Program for Fujian Natural Science Foundation Project (2019J01430).

\section{REFERENCES}

[1] Cao, S., Wang, Y., Duan, F., Zhao, W. J., Wang, Z. H., Fang, N. (2016): Coupling between ecological vulnerability and economic poverty in contiguous destitute areas, China: Empirical analysis of 714 poverty-stricken counties. - Chinese Journal of Applied Ecology 27(8): 2614-2622.

[2] Chen, S., Chen, D. (2018): Air Pollution, Government Regulations and High-quality Economic Development. - Economic Research Journal 2: 20-34.

[3] Cheng, C. P., Qiu, Y. T. (2018): The Theory and Practice for Sustained High Growth of China's Economy Since the Reform and Opening-up. - China Soft Science 2: 160-167.

[4] Fang, C., Zhou, C., Gu, C., Chen, L., Li, S. (2016): Theoretical analysis of interactive coupled effects between urbanization and eco-environment in mega-urban agglomerations. - Acta Geographica Sinica 71: 531-550.

[5] Guo, Y., Wang, H., Nijkamp, P., Xu, J. (2015): Space-time changes in interdependent urban-environmental systems: A policy study on the Huai River Basin in China. - Habitat International 45: 135-146.

[6] Hu, Y., Yang, R. (2012): Study on the coupling mode of economy and eco-environment of the lake basins in plateau. - Inquiry into Economic Issues (5): 173-178.

[7] Hu, A. G. (2017): China Entering Post-industrial Era. - Journal of Beijing Jiaotong University 16(1): 1-16.

[8] Jiang, H., He, J. (2010): The Dynamic Coupling Model of Coordinated Development between Regional Economic and Ecological Environment Systems Based on Jiangsu Province. - Soft Science 24(3): 63-68.

[9] Jin, B. (2018): Study on the "High-Quality Development" Economics. - China Industrial Economics: 5-18.

[10] Lei, D., Zhao, W., Huang, Y., Cheng, S., Liu, C. (2015): Research on the Coupling Coordination Relationship between Urbanization and the Air Environment: A Case Study of the Area of Wuhan. - Atmosphere 6(10): 1539-1558.

[11] Li, X., Shi, X., He, J., Liu, X. (2011): Coupling Simulation and Optimization to Solve Planning Problems in a Fast-Developing Area. - Annals of the Association of American Geographers 101(5): 1032-1048.

[12] Li, Y., Li, Y., Zhou, Y., Shi, Y., Zhu, X. (2012): Investigation of a coupling model of coordination between urbanization and the environment. - Journal of Environmental Management 98(1): 127-133.

[13] Li, H., Gao, Q. (2017): Scientific and Technological Progress, Marine Economic Development and Ecological Environmental Change. - East China Economic Management (31): 100-107.

[14] Li, H., Gao, Q., Wu, F. (2017): Ecological environment response to marine economy development and the influence factors in Bohai Bay Rim Area. - China Population, Resources and Environment 27: 36-43.

[15] Liao, M., Wang, Y. (2019): China's Energy Consumption Rebound Effect Analysis Based on the Perspective of Technological Progress. - Sustainability 11: 1461.

[16] Liu, G., Shen, L., Liu, X. (2007): Harmonious Interactions between Economic Development and Ecological Environment Conservation in Resource-Rich and EconomyPoor Regions: A Case in Yulin City, Shaanxi Province. - Resources Science 4: 18-24. 


$$
-11083 \text { - }
$$

[17] Liu, D., Yang, Y. (2011): Coupling coordinative degree of regional economy-tourismecological environment: a case of Anhui Province. - Resources \& Environment in the Yangtze Basin 20(7): 892-896.

[18] Liu, J. (2016): Framing sustainability in a telecoupled world. - Acta Ecologica Sinica (23): 7870-7885.

[19] Nie, H., Jia, R. (2011): The Productivity and Misallocation of Resources of Manufacturing Enterprises in China. - The Journal of World Economy (7): 27-42.

[20] Shen, K., Li, Z. (2011): The Driving Force and Restraints on China's Economic Growth. - Economic Perspectives 1: 26-32.

[21] Sheng, Y. (2018): Construct the modern economic system and promote the high-quality economic development - the essential characteristic of China's economic development in the new era. - Qiushi.

[22] Shi, B., Ren, B. (2018): A Measurement of China's Provincial Economic High Quality Development. - On Economic Problems 4: 1-6.

[23] Wang, L., Su, J., Huang, X. (2013): Analysis on the coupling and coordination degree between economic development and ecological environment of the forest park in Shanxi province. - Journal of Agrotechnical Economics 8: 98-104.

[24] Wang, Y. (2018): Study on the coupling relationship between the efficiency of economic development and the quality of ecological environment along the Silk Road Economic Belt. - Statistics \& Decision 1: 141-144.

[25] Wu, M., Lang, D. (1997): Research On the Coordination Degree of EnvironmentEconomy System. - Environmental Pollution \& Control 19(2): 20-23.

[26] Yongxiang (2014): Empirical Study of the Coupling Coordination Relationship of urbanization and ecological environment in Nanchang and Jiujiang urban belts. - Journal of Interdisciplinary Mathematics 17: 16.

[27] You, H. (2016): Quantifying the coordinated degree of urbanization in Shanghai, China. Quality \& Quantity 50(3): 1273-1283.

[28] Zhang, P., Hu, Y., Zhao, M. (2010): The Coordinated Perspective of Economic Development and Eco-environment in Northen Agriculture and Stock Raising Interlace Area. - China Population, Resources and Environment 20: 150-154.

[29] Zhang, R., Jiao, H. (2015): Coupling and Coordinating between Economic Development and Ecological Environment in the Pan Yangtze River Delta. - Resources and Environment in the Yangtze Basin 24: 719-727.

[30] Zhang, X., Xie, Y. (2016): County Urbanization: Ecological Notion, Coupling Mechanism and Realization Path. - Journal of Agro-Forestry Economics and Management 15(6): 727-734.

[31] Zhuang, G., Zhu, S., Yuan, L., Tan, X. (2014): Ranking of Low-carbon Development Level of Chinese Cities and International Comparative Study. - Journal of China University of Geosciences (Social Sciences Edition) 14: 17-23, 138. 